\title{
Commentary on Impact of COVID-19 and Lockdown on Children with ADHD and Their Families-An Online Survey and a Continuity Care Model
}

\author{
Sharad Philip ${ }^{1}$ \\ ${ }^{1}$ Department of Psychiatry, NIMHANS, Bangalore, Karnataka, India
}

J Neurosci Rural Pract:2021;12:222-222

The pandemic and consequent restrictions on movements and services have been well documented. Amongst those who have been impacted but whose voices have remained unheard are children and adolescents with developmental disorders and mental ill health. This study "Impact of COVID-19 and Lockdown on Children with ADHD and Their Families: An Online Survey and a Continuity Care Model" by Shah et $\mathrm{al}^{1}$ examining a continuity of care service model for children with ADHD (attention deficit hyperactivity disorder) has comprehensively examined how such a service model might be tailored to become an alternative or adjunctive mode of service delivery. I congratulate the investigators and authors for their optimistic perspective of looking at the pandemic as an opportunity to effect behavioral change amongst parents of children with ADHD. This has led to a desirable outcome in a proportion of the children and their families being serviced. Methodological limitations, mostly on account of the pandemic and its restrictions, hindering the generalizability of the results also have been outlined very well alongside how future studies could overcome those limitations. Intuitively, in the coming months and years, such a modality spanning distance would become a norm. Details for contacting patients are also soon to be digitized and would be available
Address for correspondence Sharad Philip, MD, Department of Psychiatry, NIMHANS, Bangalore 560029, Karnataka India, (e-mail: sharadphilipdr@gmail.).

without location restrictions thanks to the new national digital health blueprint mission. ${ }^{2}$

It is an encouraging testament to the strength and resilience of the Indian family that a significant proportion of families reported symptomatic worsening yet coped through the pandemic and its restrictions. This is part of a pilot study and I wish the authors and investigators the very best in their efforts to complete the study and look forward to reading it. As practitioners, we can learn the effective use of freely available online platforms and applications to better cater to the needs and interests of our clients and their families.

\section{Conflict of Interest}

None declared.

\section{References}

1 Shah R, Raju VV, Sharma A, Grover S. Impact of COVID-19 and lockdown on children with ADHD and their families-an online survey and a continuity care model. J Neurosci Rural Pract 2021;12(1):71-79

2 NDHM-National Digital Health Mission Retrieved from. The NDHM ecosystem. Available at: https://nha.gov.in/home/ ndhm Accessed November 12, 2020
DOI https://doi.org/ 10.1055/s-0040-1721542 ISSN 0976-3147. (c) 2021. Association for Helping Neurosurgical Sick People. This is an open access article published by Thieme under the terms of the Creative Commons Attribution-NonDerivative-NonCommercial-License, permitting copying and reproduction so long as the original work is given appropriate credit. Contents may not be used for commercial purposes, or adapted, remixed, transformed or built upon. (https://creativecommons.org/licenses/by-nc-nd/4.0/)

Thieme Medical and Scientific Publishers Pvt. Ltd. A-12, 2nd Floor, Sector 2, Noida-201301 UP, India 